\title{
Access Monitoring Is Worthwhile and Valuable
}

\author{
Anatole Besarab \\ Division of Nephrology and Hypertension, Department of Medicine, Henry Ford Hospital, Detroit, Mich., USA
}

\author{
Key Words \\ Arteriovenous fistula $\cdot$ Vascular access · Surveillance/ \\ monitoring technique $\cdot$ Percutaneous transluminal \\ angioplasty
}

\begin{abstract}
During the past several years, a limited number of small clinical trials have questioned the role of surveillance in the management of vascular accesses, since the prolongation of access longevity until replacement was not altered. Although prolongation of access life span is an important endpoint, it is not the only one. Reduction in thrombotic events reduces the risks to the patient resulting from loss of access patency. The body of evidence suggests that the detection of stenosis and prevention of thrombosis are valuable. When a test indicates the likely presence of a stenosis, venography or fistulography should be used to definitely establish the presence and the degree of the stenosis. In most cases, angioplasty should be performed if the stenosis is greater than $50 \%$ by diameter. The value of routine use of any surveillance technique for detecting anatomic stenosis alone without concomitant functional assessment by measurement of access flow, venous pressure, recirculation, or other physiologic parameter has not been established. Stenotic lesions should not be repaired merely because they are present. If such correction is performed, then intra-procedural studies of access flow or intra-access pressure prior to and following percutaneous translumi-
\end{abstract}

nal angioplasty should be conducted to demonstrate a functional improvement with a 'successful' percutaneous transluminal angioplasty.

Copyright @ 2006 S. Karger AG, Basel

\section{Introduction}

Hemodialysis is the most widely used mode of treatment of renal failure in the United States and Europe. Adequate vascular access for hemodialysis is the most important component determining the success or failure of dialytic therapy. A vascular access that reliably and consistently delivers a blood flow sufficient to meet the prescribed $\mathrm{Kt} / \mathrm{V}$, while at the same time has few complications, needs little maintenance, and no monitoring or surveillance, would be the ideal for every patient. Such an access does not exist; however, the autologous arteriovenous fistula (AVF) comes closest $[1,2]$.

Access problems are a daily occurrence in busy dialysis units. Low blood flow rates and loss of patency limit dialysis delivery, extend treatment times, and, in too many cases, result in underdialysis that leads to increased morbidity and mortality [3]. Between 1991 and 2001, the incidence of vascular access events in patients undergoing hemodialysis rose by $22 \%$ [4]. Thrombosis is the leading cause of loss of vascular access patency. Thrombosis increases health care spending $[5,6]$ and adversely affects quality of life [7]. Vascular access-related complications account for $15-20 \%$ of hospitalizations among end-stage

\section{KARGER}

Fax +41613061234

E-Mail karger@karger.ch

www.karger.com
(C) 2006 S. Karger AG, Basel

0253-5068/06/0241-0077\$23.50/0

Accessible online at:

www.karger.com/bpu
Anatole Besarab, MD, Director of Clinical Research

Division of Nephrology and Hypertension

Department of Medicine, Henry Ford Hospital

Detroit, MI 48301 (USA)

Tel. +1 313916 2713, Fax +1 313916 2554, E-Mail abesarab@ghsrenal.com 
renal disease patients undergoing hemodialysis [5]. Prevention of access dysfunction by maintaining adequate flow translates into a policy of 'dialysis dose protection', whereas preventing thrombosis reduces risks to the patients and improves their quality of life. Thrombosis is associated with additional risks to the patient not presented with simple percutaneous transluminal angioplasty (PTA) [8]. One of the most common patient fears is access thrombosis.

Failure to detect access dysfunction has consequences on morbidity and mortality $[3,4]$. In a recent study of 721 randomly selected patients from all 22 chronic hemodialysis units in northeast Ohio (USA), barriers found to significantly $(\mathrm{p}<0.001)$ and independently relate to inadequate dialysis dose delivery were patient noncompliance, low dialysis prescription, catheter use, and access thrombosis [9]. Every 0.1 decrease in $\mathrm{Kt} / \mathrm{V}$ was independently and significantly $(\mathrm{p}<0.05)$ associated with $11 \%$ more hospitalizations, $12 \%$ more hospital days, and a USD 940 increase in Medicare inpatient expenditures. Vascular access-related complications accounted for $24 \%$ of all hospital admissions [10]. The reader is referred to the Kidney/Dialysis Outcomes Quality Initiative (K/ DOQI) Hemodialysis Adequacy guidelines [11] for additional information on the importance of achieving the prescribed dialysis dose with regard to mortality.

\section{K/DOQI and Vascular Access}

In 1997, the National Kidney Foundation published the K/DOQI guidelines for the improvement in renal care [12]. The two major recommendations that came from the vascular access workgroup with the initial [12] and the subsequent revision in 2000 [13] were to (1) augment the construction of autologous native AVFs, and (2) detect hemodynamically significant stenosis likely to produce thrombosis of the access. The current workgroup believes that the goals still apply (guidelines to be published in spring 2006).

Through the year 2003, several analyses have shown that we have been very slow to change and have even fallen short of our own expectations in constructing AVF [14]. Although the National Vascular Access Improvement Initiate driven by the Center for Medicare and Medicaid Services and emphasizing a fistula first approach has increased the rate of construction of AVF in the USA, I am unsure whether the rate can be increased to reach a prevalence rate of $66 \%$ quality AVF by 2009 , as desired by the Center for Medicare and Medicaid Services [15].
The same lack of progress applies to access surveillance. Once an access has been constructed, most dialysis centers do not employ a multifaceted quality assurance program to detect vascular accesses at risk for thrombosis, track access complication rates, and implement procedures that maximize access longevity. Even at centers that try, the responsibility is frequently placed into the hands of one individual. It is not feasible for any individual to manage all aspects of access care. Multidisciplinary teams must be formed at each dialysis center [16, 17] with a vascular access coordinator if possible. The lack of consensus as to 'which test is best' and the lack of investment into surveillance by large dialysis organizations has made the dynamic pressure test the choice by default [18], even though the original thresholds for referral which are still used are not appropriate in modern high-efficiency dialysis using large bore needles.

The current workgroup has developed explicit guidelines regarding which surveillance tests are best used to evaluate a given access type and when and how to intervene to reduce thrombosis and underdialysis. Surveillance/monitoring $(\mathrm{S} / \mathrm{M})$ using specific assessments must be combined with regular assessment of clinical parameters of the arteriovenous access and dialysis adequacy. Data from the clinical assessment and dialysis adequacy measurements should be collected and maintained for each patient's access and made available to all the staff. The data should be tabulated and tracked within each dialysis center as part of a Quality Assurance/Continuous Quality Improvement program. Whatever the size and composition of the team, its most important function is to work proactively to ensure the patient's delivery of the adequate dialysis dose by maintaining access function and patency.

Despite the strong position taken by the workgroup concerning the importance of access $\mathrm{S} / \mathrm{M}$, recent studies have challenged the value or efficacy of such S/M. The basic purpose of all $\mathrm{S} / \mathrm{M}$ is to detect 'asymptomatic' stenoses before they are severe enough to produce inadequate dialysis or lead to thrombosis. Such stenoses are defined as being 'hemodynamically significant'. Although there is a consensus that monitoring of the access blood flow $\left(\mathrm{Q}_{\mathrm{A}}\right)$ or pressures is useful in predicting stenosis or thrombosis $[13,14,18,19]$, several studies have reported that the use of these $\mathrm{S} / \mathrm{M}$ techniques may not alter the outcome [20-22]. If early diagnosis and intervention for stenosis with angioplasty does not alter the 'life expectancy' of the access [23], what is the purpose? More intervention may increase the costs of care but not the useful duration of any given access (i.e. its useful lifespan until 
replacement). Do we need to look at other methods for preventing thrombosis in our patients besides those of access longevity? Is reduction in thrombosis itself a reasonable goal? It is incumbent on us to review our methods of evaluation, placement, use, and repair of dysfunctional vascular access and evaluate what the data say.

However, in order to have a rational discussion, we must first define our terms.

\section{Definitions}

The following definitions will be used throughout this paper.

Monitoring. Physical examination (look, touch, listen) of the vascular access to detect physical signs that suggest the presence of dysfunction [24]. These basic skills have been lost at most centers in favor of technology and need to be retaught to all individuals who perform hemodialysis procedures.

Surveillance. Periodic evaluation of the vascular access by means of specialized tests that may involve special instrumentation, for which an abnormal test result suggests the presence of dysfunction. Such tests include $Q_{A}$, access resistance, intra-access pressure $\left(\mathrm{P}_{\mathrm{IA}}\right)$, and access recirculation. These tests measure the adequacy of access function. Measurements such as the urea reduction ratio (URR) and $\mathrm{Kt} / \mathrm{V}$ measure the effect of inadequate access function on the delivery of dialysis. Duplex Doppler ultrasound (DDU) is unique among the tests since it is not only able to measure $Q_{A}$ but also visualize and quantify the severity of any stenoses present [25]. Surveillance and monitoring are complementary.

Diagnostic Testing. Specialized testing that is prompted by some abnormality or other medical indication specifically undertaken to diagnose the cause of the vascular access dysfunction. The current gold standard is angiography, but DDU can be used for this function as well [25, 26]. In most cases, the individual is sent to a radiologic center where contrast visualization can occur [27]. In some cases, intra-access angioscopy and ultrasound can be performed [28]. Magnetic resonance angiography can also be used to characterize the anatomic presence of stenosis [29-31], as well as to quantitate flow [32]. A variety of $\mathrm{Q}_{\mathrm{A}}$ measurements are available; currently, dilution ultrasound is the 'gold standard'.

Intervention. Performance of a procedure that dilates a stenosis, stents it, bypasses it, or resects it. The most common procedure performed for stenosis is PTA using high-pressure balloons with burst limits above $30 \mathrm{~atm}$. If

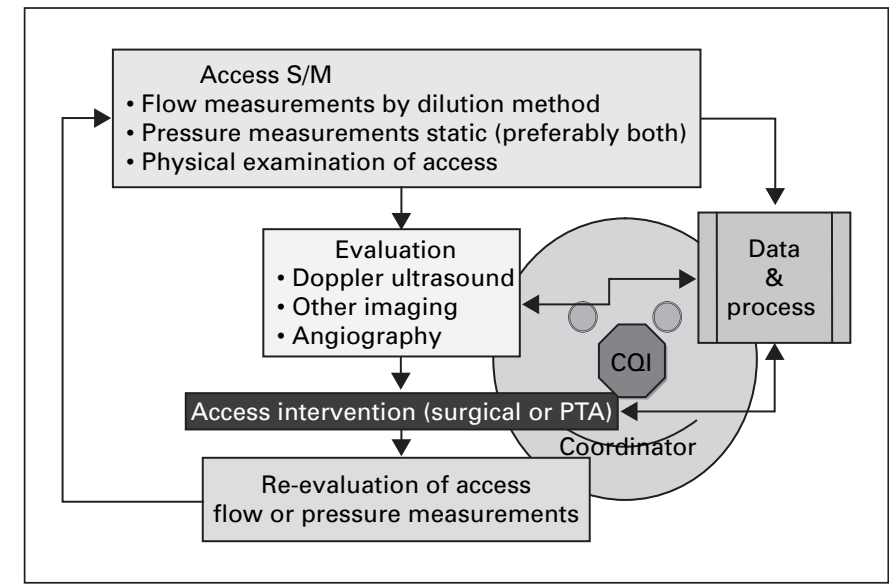

Fig. 1. Flow diagram depicting a continuous quality surveillance/ intervention process in which a pressure or flow technique is used, accesses with abnormality are studied, stenoses identified and corrected prior to thrombosis, and the measurement is repeated to assure that the PTA/surgical procedure was successful.

the access is thrombosed, a variety of techniques are available to remove the clot. Special devices have been developed for this procedure. Thrombolytics may or may not be used depending on the type of access.

\section{The S/M Process}

In a proper operational program, asymptomatic but hemodynamic stenoses are detected through a systematic $\mathrm{S} / \mathrm{M}$ program, then referred for study, intervened upon, and checked to verify that the hemodynamics or functional abnormality has 'improved' (fig. 1). A functionally significant stenosis is currently defined as a reduction greater than $50 \%$ in normal vessel diameter, accompanied by hemodynamic or clinical abnormality, such as abnormal recirculation values, elevated venous pressures, decreased blood flow, swollen extremity, unexplained reduction in $\mathrm{Kt} / \mathrm{V}$, or elevated negative arterial prepump pressures that prevent increasing to acceptable blood flow [33]. This definition evolves from an analysis of hemodynamics and clinical correlation. Prospective M/S should provide the ability to salvage vascular access sites through planning, coordination of effort, and elective corrective intervention rather than through urgent procedures or replacement [34]. A number of surveillance methods are available: sequential $\mathrm{Q}_{\mathrm{A}}$, sequential dynamic or static pressures, recirculation measurements, physical examination, and combinations. 


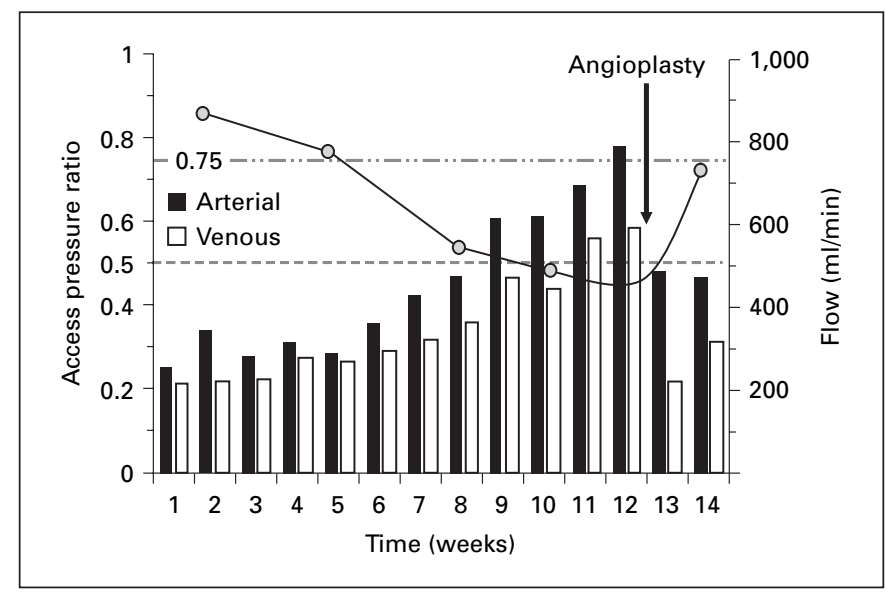

Fig. 2. Access pressure/mean arterial pressure ratios and $\mathrm{Q}_{\mathrm{A}}$ of a 73-year-old diabetic male; tapered graft, $4-6 \mathrm{~mm}$ at the arterial (brachial artery) anastomosis increasing to $7 \mathrm{~mm}$ at the venous anastomosis (axillary vein). Changes in a vascular access graft over time depicting the reciprocal changes in pressure and flow until a threshold is reached at which a PTA restores the original function of the graft.

\section{Basic Physiology/Basic Tenant for S/M}

The basic tenant for vascular access monitoring and surveillance is that stenosis develops at variable intervals in the great majority of vascular accesses, and if detected and corrected, underdialysis can be minimized or avoided and the rate of thrombosis reduced. The rationale for surveillance depends on the 'dysfunction' hypothesis: stenosis produces graft dysfunction lowering $\mathrm{Q}_{\mathrm{A}}$ and/or altering pressure profiles, and this dysfunction reliably precedes and accurately predicts thrombosis [35]. The usefulness of flow or pressure surveillance depends on the accuracy of the measurements themselves so that accurate confirmation of hemodynamic dysfunction is proven prior to correction of the stenosis. Unfortunately, both $\mathrm{Q}_{\mathrm{A}}$ and pressure vary in patients during and, more importantly, between dialysis sessions. This makes a single measurement an inaccurate predictor of stenosis, and therefore, also of thrombosis. The only rational means to detect an evolving lesion is to perform analysis using multiple repetitive measurements so that inappropriate referrals are not made. Currently, there is very little quality assurance of 'success' of an intervention other than an anatomical one.

Knowledge of the 'best function of a given access' is crucial to the interpretation of any S/M technique. For an arteriovenous graft, this is typically shortly after the first use, since neointimal hyperplasia progressively increases

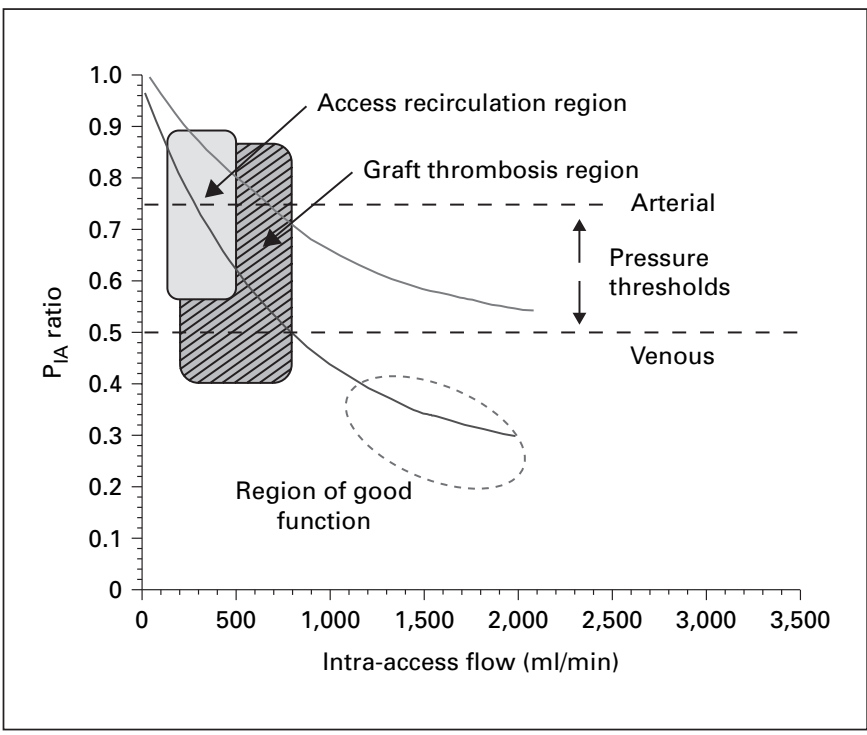

Fig. 3. Effect of graft venous outlet stenosis. Relationship between $\mathrm{Q}_{\mathrm{A}}$ and $\mathrm{P}_{\mathrm{IA}}$ in grafts. Note the inverse relationship. As venous outflow stenosis secondary to neointimal hyperplasia develops, $\mathrm{Q}_{\mathrm{A}}$ decreases while static pressure increases. Note that access recirculation is a very late manifestation of access dysfunction.

resistance with time. The pressure drop across the access from artery to vein is set by the mean arterial pressure minus the central venous pressure. $Q_{A}$ results depend on many variables, including those of the graft diameter and the patient's ability to augment cardiac output in response to the fistula. As shown in figure 2, use of an arterial taper to reduce $\mathrm{Q}_{\mathrm{A}}$ and avoid 'steal' produces a relatively low $\mathrm{Q}_{\mathrm{A}}$ and relatively low $\mathrm{P}_{\mathrm{IA}}$. A flow $<800$ and $<500 \mathrm{ml} / \mathrm{min}$ occurred within 5 and 10 weeks, respectively, as neointimal hyperplasia developed. However, the best flow in this access was $<900 \mathrm{ml} / \mathrm{min}$ when measured 3.5 weeks after creation. Stenosis is manifested by both a decrease in $\mathrm{Q}_{\mathrm{A}}$ as well as progressive increases in arterial and venous segment $\mathrm{P}_{\text {IA }}$. PTA is successful, but the rapidity of the initial dysfunction and the small reserve forecast repeated and frequent procedures in this access. However, the S/M approach in this marginal access is likely to differ from that of a 'very good' access, which is one whose initial 'best flow' was in excess of $1,500 \mathrm{ml} / \mathrm{min}$ when first evaluated.

As shown in figure 3, the relationship between $\mathrm{Q}_{\mathrm{A}}$ and $\mathrm{P}_{\mathrm{IA}}$ is inverse. If an outflow stenosis develops from neointimal hyperplasia and increases resistance, pressure will increase and flow decrease. An initially well-functioning graft with an $\mathrm{Q}_{\mathrm{A}}$ approaching $21 / \mathrm{min}$ (usually in the upper arm) will manifest decreasing flow, as both the ar- 
terial and venous pressure slowly increase with the development of outflow tract stenosis. Since the intimal hyperplasia process progresses variably with time, its detection requires sequential measurements of flow or pressure or both to detect a threshold at which action should be taken. The frequency of measurements depends on the rate of progression. Note that the graft thrombosis region by flow shown in the hatched area is reached long before a graft would show recirculation, and therefore, affects the delivered dose of dialysis. The relationship between flow and degree of stenosis is distinctly non-linear. Hemodynamic simulations indicate that flow decreases by less than $20 \%$ as the stenotic process grows and decreases the luminal diameter by $40-50 \%$. Thereafter, flow decreases rapidly as the degree of stenosis increases to $80 \%$ [36]. The hyperbolic relationship between $\mathrm{Q}_{\mathrm{A}}$ and both access pressures would be expected to occur within a given access if the outflow were the only source of stenosis. Unfortunately, this is not the case. Lesions in the inflow and within the body of the access do occur, and on average, the typical access has nearly two lesions/access locations at the time of referral $[37,38]$. The lesions change the relationship between flow and pressure. As shown in figure 4, mid-graft lesions are associated with lower pressures at the venous limb, but the arterial pressure remains elevated. PTA accomplishes the same effect, increasing flow and restoring the profile 'toward' normal. With a dominant inflow lesion, both pressures would be 'low'. Stenosis at the arterial anastomosis of both grafts and fistulas causes $\mathrm{P}_{\mathrm{IA}}$ to decrease. Thus, a high basal $\mathrm{P}_{\mathrm{IA}}$ can be observed in the absence of stenosis when the flow delivered by a healthy artery is in excess of the initial capacitance of the venous system to accommodate to the flow. Because of these confounders due to anatomic factors and the location of stenosis, there is little, if any, correlation between a single measurement of flow and $\mathrm{P}_{\mathrm{IA}}$ [39]. None would be expected.

The above considerations have two practical applications. First, it is immediately apparent that the quality and physical dimensions of the artery and vein will determine the initial access function; the major determinant of $\mathrm{Q}_{\mathrm{A}}$ in a given patient will be determined by the capacity of the artery to dilate, its general 'health', and the patient's general cardiovascular health. In general, arteries at more distal sites have less capacity to deliver flow than more proximal sites, i.e. radial $<$ brachial $<$ axillary $<$ femoral. Arteries that are calcified or affected by atherosclerosis will result in lower $\mathrm{Q}_{\mathrm{A}}$, whether autologous fistulas or graft. If the artery is healthy, the flow capacity will be determined by the characteristics of the vein used

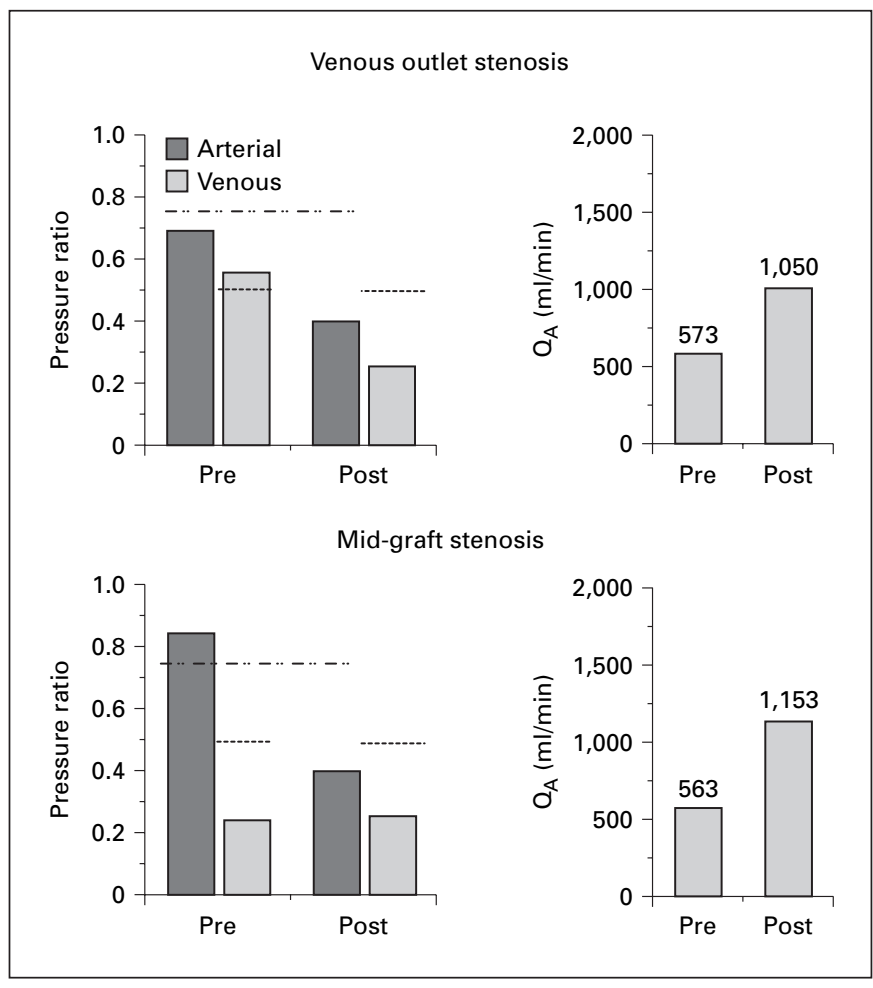

Fig. 4. Depiction of the effect of the location of stenosis on hemodynamic (functional) parameters of $\mathrm{Q}_{\mathrm{A}}$ and static pressures. Stenosis always reduced flow, but the location is important in interpreting static pressures (see text for details). PTA restores flow and normalizes the pressure profile.

in access construction. Too small a vein will limit the flow in both AVF and arteriovenous graft. Unfortunately, arterial disease is not uncommon; access inflow stenosis occurs in one third of the cases referred to interventional facilities with clinical evidence of venous stenosis or thrombosis [40]. This is much higher than the $5 \%$ rate that has been traditionally reported [41].

Second, serial measurements of pressure or flow within each patient are more valuable in detecting a stenosis than any isolated measurements of either absolute $\mathrm{P}_{\mathrm{IA}}$, normalized ratio, or $\mathrm{Q}_{\mathrm{A}}$. I will not discuss the various modalities available to measure $\mathrm{Q}_{\mathrm{A}}$ or access pressures. As illustrated in figure 5 (many more pressure measurements were made than actually shown), it is important that measurements be made repeatedly and that criteria be developed for when to act with intervention. In the case illustrated, two PTAs (arrows) were performed based on an increase in the normalized systolic pressure ratio above 0.40 [42] but could have been just as easily driven by an absolute flow rate of $<800 \mathrm{ml} / \mathrm{min}$. How- 


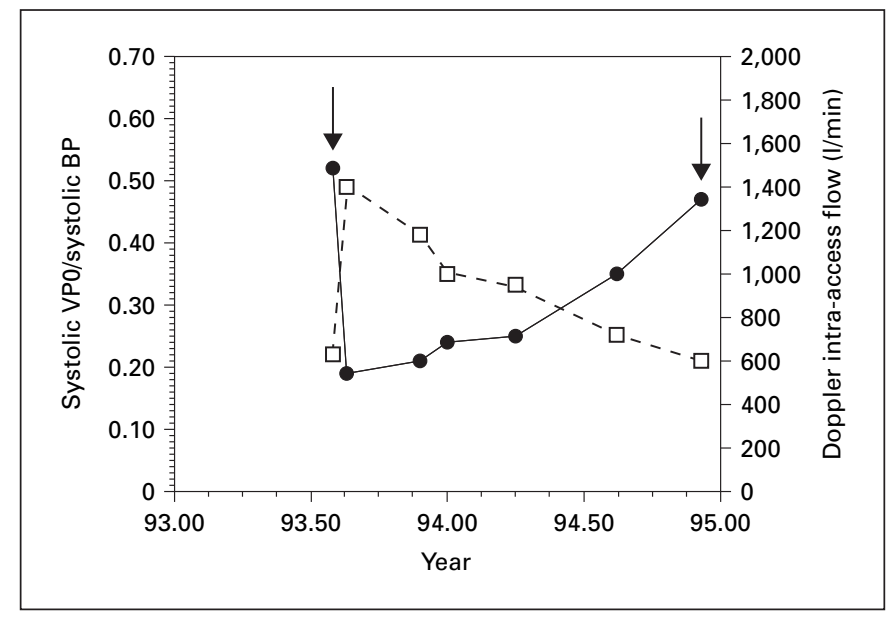

Fig. 5. An illustrative case depicting the inverse relationship between flow and static pressure ratio in a graft vascular access. VP0 $=$ Venous pressure at zero dialyzer blood flow; $\mathrm{BP}=$ blood pressure.

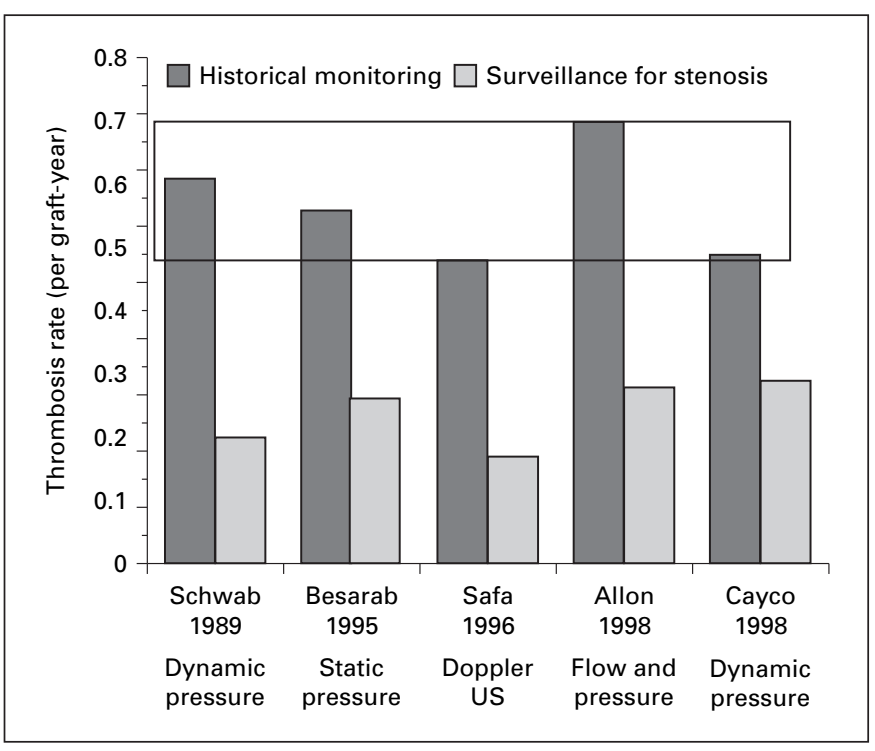

Fig. 6. Compilation of studies that used historical controls showing the effect of $\mathrm{S} / \mathrm{M}$ on thrombosis rates. Note that in each study implementation of an $\mathrm{S} / \mathrm{M}$ technique reduced thrombosis rate by at least $40 \%$ and often by over half compared with the historical period. The reduction in thrombosis rate is independent of the $\mathrm{S} / \mathrm{M}$ technique chosen.

ever, a criterion using a decrease in flow of 30\% [43] would have led to premature PTA a year before it was necessary.

It is not clear whether $\mathrm{Q}_{\mathrm{A}}$ measurements performed at a monthly frequency provide sufficient data stability to make decisions. Until additional studies are performed to determine the optimal frequency, more frequent measurements are recommended.

\section{What Are the Issues in the Efficacy/Value of S/M?}

\section{Does S/M Prevent Thrombosis? Yes}

The usefulness of S/M depends on the accurate prediction of thrombosis so that stenosis can be corrected prior to thrombosis; the goal of any surveillance method is to detect access stenosis in a timely way so that appropriate correction can be undertaken prior to thrombosis. This lead time may be measured in weeks or months. A large body of evidence indicates that prospective $\mathrm{S} / \mathrm{M}$ to detect stenosis reduces the rate of thrombosis, although at the expense of increased procedures [16, 42, 44-48]. As shown in figure $6, \mathrm{~S} / \mathrm{M}$ reduced the thrombosis rate by 41 to $67 \%$. Note that in the studies cited, the historic thrombosis rate ranged from 0.5 to 0.7 events per access-year at risk. The study by Schwab et al. [44] included both grafts and autologous AVF; the others analyzed only grafts. Although none of these studies were randomized, they do indicate that surveillance, and even monitoring, when performed well [49], can reduce the event rate.

The approach and role of S/M in AVF may differ. Since autologous fistulas maintain patency at lower flows than grafts, the criteria for intervention in AVF are not as well established. One study has established the value of $Q_{A}$ surveillance in AVF, the positive predictive value, negative predictive value, sensitivity, and specificity of the ultrafiltration $\mathrm{Q}_{\mathrm{A}}$ method for vascular access stenosis (OABF CritLine III) being 84.2, 93.5, 84.2, and 93.5\%, respectively. The vascular access thrombosis rate in 50 $\mathrm{Q}_{\mathrm{A}}$ surveillance patients was lower $(2 / 50,4 \%)$ than in 94 patients who were not followed with flow measurements $(16 / 94,17 \%)(p=0.024)$ [50]. However, the urge to intervene with PTA to prevent thrombosis must be balanced by the observations that PTA almost invariably triggers repeated need for the same procedure. The optimal care of such patients requires individualization and not rigid application of protocols.

In general, when using flow, the period over which the prediction of thrombosis is made shortens as the absolute $\mathrm{Q}_{\mathrm{A}}$ decreases, i.e. approximately $950-1,000 \mathrm{ml} / \mathrm{min}$ when forecasting 3-6 months [51, 52], and $<600 \mathrm{ml} / \mathrm{min}$ if forecasting less than 2 months [53]. This is illustrated in our own work in which we measured flow by dilution ultrasound every 2 weeks for the first 3 months (6 data points) 


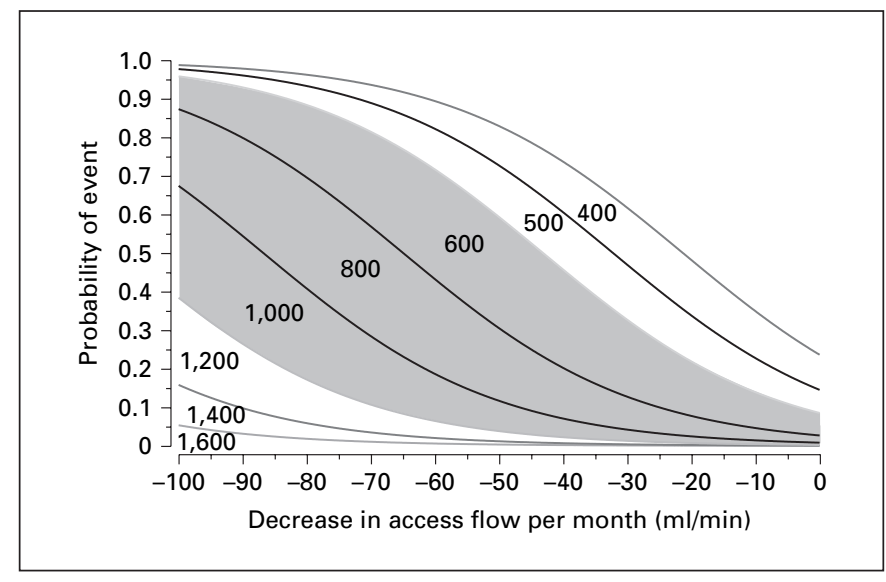

Fig. 7. Probability of a vascular access thrombosis occurring within a 3-month period is dependent not only on the absolute flow at any time but also on the rate if there is a change in flow.

following new graft construction and monthly thereafter to determine the probability of thrombosis [54]. The decrease in flow from the initial value was obtained by regression analysis. As can be seen in figure 7, the likelihood of thrombosis during the second 3-month observation period increased with lower initial 'best' flow and with the decrease in flow per month. An access with an initial flow of $600 \mathrm{ml} / \mathrm{min}$ and a $20-\mathrm{ml} / \mathrm{min}$ decrease in flow per month has a lower probability of thrombosis $(22 \%)$ than an access with an initial flow of $1,200 \mathrm{ml} / \mathrm{min}$ and a decrease in flow of $100 \mathrm{ml} / \mathrm{min}(38 \%)$, even though the absolute flow is much lower in the former $(540 \mathrm{ml} / \mathrm{min})$ than in the latter $(900 \mathrm{ml} / \mathrm{min})$ at the beginning of the observation period. Our results are in keeping with results by others $[55,56]$.

The above figure provides data on the probability, not the certainty, of an event, and the action level has to be determined by other considerations. Over a 3-month period observation, grafts can clot in the absence of any stenosis and often do so at flows equal to those that remain patent, usually in excess of $1,100 \mathrm{ml} / \mathrm{min}$. $\mathrm{P}_{\mathrm{IA}}$ in these cases remains unchanged. Grafts that require intervention or thrombose due to an anatomical lesion have much lower $\mathrm{Q}_{\mathrm{A}}$, i.e. 656 and $609 \mathrm{ml} / \mathrm{min}$, respectively. Others have found that even at flows above the threshold $(>800 \mathrm{ml} / \mathrm{min}$ ), the incidence of thrombosis may be as high as 20\% per 6-month period [57]. Similarly, even with flows in the highest quartile $(>1,395 \mathrm{ml} / \mathrm{min})$ a thrombosis rate of $9 \%$ over a period of 3 months (annualized risk would be $36 \%$ ) was detected in these grafts [51]. These observations clearly imply that stenosis per se with its ac- companying low flow is not a sufficient substrate to produce thrombosis in a predictable fashion. Other factors such as inflammation [58], procoagulant dysfunction [59], presence or absence of diabetes, and the use of angiotensin-converting enzyme inhibitors or angiotensin receptor blockers [60] all contribute to the process. Thrombosis rates in grafts in the absence of S/M have been noted to vary from 0.5 to over 2.0 episodes per access-year at risk. Such differences emphasize the role of these factors including cannulation techniques by the staff. The efficacy of S/M cannot be demonstrated if these other factors produce a high basal thrombosis rate in the absence of stenosis.

\section{Does S/M Prolong Access Longevity? We Do Not Know! Is It Relevant?}

The statement that 'it is widely accepted that surveillance with correction of stenosis before thrombosis prolongs hemodialysis graft survival' is incorrect. There have been virtually no large studies addressing this important aspect. The study by Lumsden et al. [61] initially refuted the concept that prophylactic or pre-emptive PTA would decrease graft thrombosis. In a study of 64 patients with a stenosis of $50 \%$ by diameter $(50 \% \mathrm{D})$ identified by DDU and confirmed by angiography, pre-emptive PTA produced no change in 6- or 12-month patency. Because of confounding issues, a subanalysis was performed on 21 'virgin' grafts that had not previously clotted or required any intervention [62]. Pre-emptive PTA from the time of diagnosis of stenosis reduced the thrombosis rate from 0.44 to 0.10 episodes/patient-year at risk. Both rates were much lower than the rate of 0.91 in patients without virgin grafts.

The small sample size in this and all other prospective studies has limited assessment of efficacy. One prospective study using static pressure has been performed [20]. Although the study itself was well designed, it was flawed by the surveillance technique. The methodology for deriving the $\mathrm{P}_{\mathrm{IA}}$ ratio differed from that originally described [42]. The net effect of the error was to 'falsely elevate' the fraction meeting the criterion for referral and intervention. Not surprisingly, receiver operating characteristic analysis yielded curves with areas $<0.64$ (very poor). Subsequently, 64 patients with 'elevated static venous pressure' measured in an upper extremity arteriovenous graft were randomized to intervention (they underwent angiography and repair of identified stenoses) or observation (they underwent stenosis repair only in the event of access 
Table 1. Effects of access failure

Thrombosed vascular access is a major problem
For dialysis staff
Rearrange dialysis schedule
Arrange for transportation
Interface between patient and physicians
Assist patient in coping
For the nephrologist
Deal with unhappy patient and family
Oversee logistics of resolving failure
For the patient
Cope with discomfort, pain, anxiety, and fear
Decreased quality of life
Schedule disruption
Delay of dialysis
Situation aggravated if condition precludes delay of dialysis

thrombosis or clinical evidence of access dysfunction) with the primary endpoint being access abandonment. No difference in access abandonment (14 patients in each group) during the 3.5-year study period or in the time to access abandonment was found. However, the proportion of patients with a thrombotic event was greater in the observation group $(72 \%)$ than in the intervention group $(44 \%)(p=0.04)$. The number of PTA performed in the two groups is not stated.

Two randomized studies have examined the role of access surveillance using $\mathrm{Q}_{\mathrm{A}}$ in arteriovenous grafts. In the first, Moist et al. [22] found that stenotic lesions are more commonly detected by $\mathrm{Q}_{\mathrm{A}}$ or a decrease in $\mathrm{Q}_{\mathrm{A}}$ of $20 \%$ than by 'routine surveillance' using physical exam and dynamic venous pressure surveillance $(>150 \mathrm{~mm} \mathrm{Hg})$ in a total of 112 patients. Elective PTA for lesions $>50 \% \mathrm{D}$ did not alter the thrombosis rate, rate of graft loss, time to graft loss, and overall thrombosis rate between the two groups. However, interventions increased by $30 \%$ in the intervention group. In the second study, 101 patients were randomized to 3 groups: control, flow surveillance $\mathrm{Q}_{\mathrm{A}}$ (Transonics) monthly, or stenosis detection by DDU quarterly [21]. Referral for angiogram was based on clinical characteristics in all, on $<600 \mathrm{ml} / \mathrm{min}$ in the $\mathrm{Q}_{\mathrm{A}}$ group, and on $>50 \% \mathrm{D}$ in the DDU stenosis group. $\mathrm{Q}_{\mathrm{A}}$ was measured in all 3 groups but only used for referral in the flow surveillance group. The baseline thrombosis rate was 0.7 and 0.9 per patient-year in control and $\mathrm{Q}_{\mathrm{A}}$ groups, respectively. $\mathrm{Q}_{\mathrm{A}}$ marginally increased the PTA rate (from 0.22 to 0.33 patient-year) and had no effect on the thrombosis rate. Stenosis surveillance increased the PTA rate to $0.65 /$ patient-year and reduced the thrombosis rate to $0.5 / \mathrm{pa}-$ tient-year, but as in the other trial, did not have an effect on the 2-year survival rate. In those grafts that clotted (overall 11/60), a $Q_{A}<600$ was found in $4 / 18,4 / 31$, and $3 / 11$ of the control, $\mathrm{Q}_{\mathrm{A}}$ surveillance, and stenosis groups, respectively. However, 26 of 35 patients in the stenosis group had PTA for 'stenosis'. Stenosis was present much more commonly than the action level for flow surveillance. In both studies, $20-25 \%$ of access clotted without a surveillance abnormality, which was totally unexpected.

The overriding conclusion of the studies was that surveillance using $\mathrm{Q}_{\mathrm{A}}$ and PTA in response to a threshold value of $Q_{A}$ did not alter graft survival which has to be tempered by the small sample size of the studies. Graft survival studies require a sample size of approximately 700 patients to detect an increase in graft survival of 1 year or a $33 \%$ difference in survival by 3 years [H. Feldman, University of Pennsylvania, Philadelphia, Pa., USA, pers. commun.]. The current study of the National Institutes of Health assessing the effect of Aggrenox on decreasing and thus prolonging time to first event (thrombosis or need for PTA) has a target of over 1,000 subjects in order to detect a $25 \%$ improvement in primary unassisted patency. To date, none of the published studies on grafts have included even a fifth of the required number of subjects. Smaller studies may be able to provide data on rates of intervention, economic costs, effect on patients, but not on graft longevity with or without S/M or PTA.

From the perspective of the patient, the focus on the longevity of grafts is inappropriate. The effect of thrombosis on the patient and on the staff is frequently minimized or overlooked (table 1). A dysfunctional access is a real concern to patients, since almost $60 \%$ of patients cite thrombosis of the access as one of the most feared problems associated with hemodialysis, ranking it second only to pain [63]. A clotted access if not resolved within $24 \mathrm{~h}$ alters the quality of life of not only the patient but the dialysis staff as well, due to the heightened urgency present with thrombosis as opposed to elective repair. A retrospective analysis of an incident cohort of 88 hemodialysis patients, of whom only $32 \%$ had a permanent access placed at least 14 days prior to the need for hemodialysis, demonstrated a $24 \%$ primary access failure rate due to complications [64]. During the mean study followup period of 487 days, $51 \%$ of patients had at least one access complication, resulting in the requirement for 25 fistulograms ( 0.21 per patient-year of risk) and 116 additional temporary access placements $(0.97$ per patientyear of risk) [64]. A total of 2.43 inpatient days and 1.05 outpatient encounters per year of patient risk were di- 
rectly attributed to admissions solely for such access complications.

Thus, prevention of thrombosis itself without prolongation of overall longevity is a worthy outcome.

Results of prospective surveillance in native fistulas have been more positive. In Italy, a 5-year randomized, controlled, open trial blood flow surveillance and preemptive repair of subclinical stenoses (angioplasty, open surgery, or both) with standard monitoring and intervention based upon clinical criteria alone was carried out [65]. Surveillance with blood pump flow monitoring during dialysis sessions and quarterly $\mathrm{Q}_{\mathrm{A}}$ or recirculation measurements identified 79 AVFs with angiographically proven, anatomically significant $(>50 \% \mathrm{D})$ stenosis that were then randomized to either a control group (intervention done in response to a decline in the delivered dialysis dose or thrombosis; $\mathrm{n}=36$ ) or to a pre-emptive treatment group $(n=43)$. Kaplan-Meier analysis showed that pre-emptive treatment reduced the failure rate $(\mathrm{p}=$ 0.003), and the Cox hazards model identified treatment $(p=0.009)$ and higher baseline $Q_{A}(p=0.001)$ as the only variables associated with a favorable outcome. Access survival was significantly higher in pre-emptively treated than in control AVFs $(\mathrm{p}=0.050)$, a higher post-intervention $\mathrm{Q}_{\mathrm{A}}$ being the only variable associated with improved access longevity $(p=0.044)$. This study provides evidence that active blood flow surveillance and pre-emptive repair of subclinical stenosis reduce the thrombosis rate and prolong the functional life of mature forearm AVFs, and that $\mathrm{Q}_{\mathrm{A}}>350 \mathrm{ml} / \mathrm{min}$ prior to intervention portends a superior outcome with pre-emptive action in AVFs.

Finally, a prospective controlled open trial was performed to evaluate whether prophylactic PTA of stenosis not associated with access dysfunction improves survival in native, virgin, radiocephalic forearm AVF [66]. Sixtytwo stenotic, functioning AVFs (able to provide an adequate dose of dialysis) were examined: 30 were allocated to control and 32 to PTA. Kaplan-Meier analysis showed that PTA improved AVF functional failure-free survival rates $(\mathrm{p}=0.012)$ with a 4 -fold increase in median survival and a 2.87-fold decrease in risk of failure. The Cox proportional hazard model identified PTA as the only variable associated with the outcome $(\mathrm{p}=0.012)$. PTA increased $Q_{A}$ by $323 \mathrm{ml} / \mathrm{min}(\mathrm{p}<0.001)$, suggesting that improved AVF survival is the result of increased $\mathrm{Q}_{\mathrm{A}}$. PTA was also associated with a significant decrease in accessrelated morbidity, halving the risk of hospitalization, central venous catheterization, and thrombectomy $(\mathrm{p}<0.05)$. Since prophylactic PTA of stenosis in functioning fore-

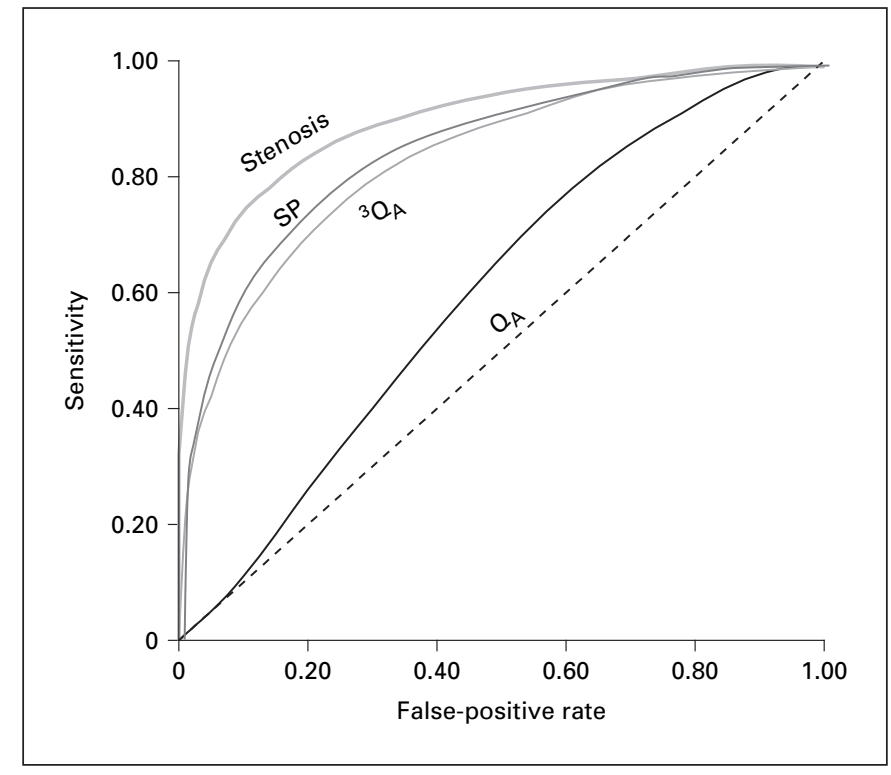

Fig. 8. Summary of figures $[35,51,55]$ depicting the receiver operating curves for various surveillance techniques in grafts. Note that an absolute flow of $25 \%$ is the least predictive of the occurrence of thrombosis (poor performance). Direct detection of stenosis by duplex Doppler sonography is best. Both a change in flow and static pressure have shown good performance in detecting stenosis (the precursor for thrombosis in most cases). $\mathrm{SP}=$ Static pressure ratio.

arm AVF improves access survival and decreases accessrelated morbidity, it supports the surveillance program for the early detection of these stenoses.

\section{Is Stenosis Detection What We Should Be Evaluating? We Do Not Know}

As important as is the accuracy of a method to detect stenosis, the goal of any surveillance method is to detect access stenosis in a timely way so that appropriate correction can be undertaken prior to thrombosis. A hemodynamically significant stenosis is the substrate for thrombosis by reducing flow, increasing turbulence, increasing platelet activation and residence time against the vessel wall. However, as previously discussed, it is not sufficient since accesses without major stenoses do thrombose and accesses with stable stenoses sometimes do not. No currently available physiologic technique is able to identify an anatomically significant 50\% stenosis with a sensitivity of $90 \%$ and a specificity greater than $80 \%$ [35]. As is reflected by the data in figure $8, \mathrm{DDU}$ is most accurate because it can directly visualize the degree of stenosis. 
Because of the accuracy of DDU in detecting the presence of a $50 \% \mathrm{D}$ stenosis [67], in some studies, DDU has been used as the reference method rather than angiography to avoid invasive procedures. Whatever method is used to document the degree of stenosis, the prevalence of a $50 \%$ stenosis is found much more frequently than a hemodynamic abnormality in static pressure or $\mathrm{Q}_{\mathrm{A}}$. In the study by Ram et al. [21], DDU found $\geq 50 \% \mathrm{D}$ stenotic lesions in over $70 \%$ of patients with grafts, but a $\mathrm{Q}_{\mathrm{A}}$ $<600 \mathrm{ml} / \mathrm{min}$ was a poor predictor of its presence or of thrombosis occurring. Our findings are similar. In a study in which all 71 grafts were angiographed to determine the prevalence and degree of stenosis, 49 were found to have at least one $50 \% \mathrm{D}$ stenosis. Of these, 37 were associated with an increase in static pressure ratio. Overall sensitivity and specificity of an increase in static pressure in detecting a 50\% stenosis were 91 and $76 \%$, respectively [68]. Paradoxically, when DDU was used to measure flow rather than to identify anatomical stenosis, sensitivity and specificity decreased. As stated previously, stenosis degree cannot alone predict the flow present or the actual $\mathrm{P}_{\mathrm{IA}}$ due to other factors.

This raises the very important issue of whether stenosis detection alone is sufficient. In the study by Ram et al. [21], detection of stenosis followed by its correction reduced the thrombosis rate. Although promising at present, there are inadequate data to answer this question. In the Canadian study, the PTA rate increased without reducing the thrombosis rate. Of importance, the two studies had significantly differing baseline thrombosis rates, i.e. 0.9 versus 0.5 events/patient-year, and the ultimate rate of thrombosis regressed toward a common mean. Differences in rates among different centers due to unknown differences in the populations (Caucasian vs. Afro-American) or in the skill sets of the dialysis staff may be a major determinant of efficacy. At the present time, I believe that a lesion which is not progressing and in which hemodynamic parameters are stable over time should not be intervened, particularly in AVF.

\section{Are Our Tools for Detection Good Enough? Yes for Now, but We Can Learn to Use Them Better}

The available data suggest that the utility of dynamic venous pressure at flows of $150-225 \mathrm{ml} / \mathrm{min}$ to predict stenosis or thrombosis is quite limited or absent in grafts [69]. Studies are needed to determine if it retains any utility in native accesses. By contrast, flow measurements,
DDU assessment for stenosis, and static pressure measurements (direct or indirect) can detect hemodynamically significant stenosis in grafts and native fistulas. Although the location of stenosis in fistulas (inflow) favors $\mathrm{Q}_{\mathrm{A}}$ over $\mathrm{P}_{\mathrm{IA}}$, no direct comparisons have been made using DDU anatomical imaging or contrast angiography to determine the accuracy of the techniques in this access type. If the prescribed $\mathrm{Kt} / \mathrm{V}$ is not delivered in a patient who is using a native fistula, the recommended ureabased method or one of the non-urea methods (ultrasound dilution, glucose pump test) are used as the measurement of access recirculation.

The current K/DOQI workgroup feels that there is insufficient evidence from the literature to suggest one preferred surveillance technique of those listed in the guidelines as 'preferred or acceptable', as the choice at a particular site is affected by many variables, mainly access type, technology, effect of operator, and cost (usually labor) [70]. Although Doppler studies are predictive of access stenosis and the likelihood of failure [71], frequency of measurement is limited by expense. In addition, in some instances, interobserver variability in flow can reduce the reliability of Doppler flow measurement [72]. Variation in the internal software used for calculating Doppler flow measurements by different manufacturers is also a factor preventing standardization. Magnetic resonance flow is accurate but expensive. Both Doppler flow and magnetic resonance are difficult to perform during dialysis sessions.

In contrast, flow measurements performed by dilution ultrasound (Transonic) and other techniques can be done on-line during dialysis, thereby providing rapid feedback. The same applies for $\mathrm{P}_{\mathrm{IA}}$. Both flow and pressure techniques have been validated in prospective observational studies [42, 43, 48, 49, 69, 73]. Measuring venous pressure is the least expensive method of surveillance for stenosis $[43,74]$. For these reasons, $\mathrm{Q}_{\mathrm{A}}$ measurement and $\mathrm{P}_{\mathrm{IA}}$ are listed as preferred. Online $\mathrm{Q}_{\mathrm{A}}$ measurements are available but require further improvements in accuracy and replicability.

Recirculation is a relatively late predictor of access dysfunction. Urea measurement for the calculation of recirculation must be done under standardized conditions. Non-urea-based recirculation measurements are very accurate but require specialized devices. Unexplained decreases in delivered dialysis dose, as measured by $\mathrm{Kt} / \mathrm{V}$ or URR, are frequently associated with venous outflow stenoses [75]. However, many other factors influence $\mathrm{Kt} / \mathrm{V}$ and URR, making them less sensitive and less specific for detecting access dysfunction. Inadequate deliv- 
ery of dialysis dose is more likely to occur with AVFs than with arteriovenous grafts.

In primary AVFs, inadequate flow through the access is the primary functional defect predictive of thrombosis and access failure (defined as thrombosis or failure to provide an adequate dialysis dose). It is currently unknown whether indirect measures of flow, such as static venous dialysis pressure, are less predictive of thrombosis and access failure in AVFs compared with arteriovenous grafts. However, combining the measurements with prepump pressures to assess for adequacy of inflow may be as effective as flow measurements. In the context of proper needle position, an elevated negative arterial prepump pressure that prevents increasing the blood flow rate to the prescribed level is also predictive of arterial inflow stenoses. Prospective comparative studies are needed. On the other hand, measurement of recirculation becomes a more useful screening tool in AVFs compared with arteriovenous grafts because flow in AVFs, unlike in arteriovenous grafts, can decrease to a level less than the prescribed blood pump flow (i.e. less than $300-500 \mathrm{ml} / \mathrm{min}$ ), while still maintaining access patency [76, 77]. Doppler ultrasound may be useful in AVF despite its increased cost [78]. Comparative studies using hemodynamic monitoring $\left(\mathrm{Q}_{\mathrm{A}}, \mathrm{P}_{\mathrm{IA}}\right)$ and DDU need to be performed before firm recommendations can be made as to the most cost-effective test.

Regular assessment of physical findings (monitoring) may enhance an organized surveillance program to detect access dysfunction. Specific findings predictive of venous stenosis include edema of the access extremity, prolonged bleeding after venipuncture (in the absence of excessive anticoagulation), and changes in the physical character- istics of the pulse or thrill in the graft $[79,80]$. Physical examination is a useful screening tool to exclude low flow $(<450 \mathrm{ml} / \mathrm{min})$ in grafts with impending failure [24].

\section{Conclusions}

The body of evidence suggests that detection of stenosis and prevention of thrombosis are valuable. When a test indicates the likely presence of a stenosis, venography or fistulography should be used to definitively establish the presence of and the degree of the stenosis. Currently, there is agreement with the recommendations of the Society of Cardiovascular and Interventional Radiography that in most cases angioplasty should be performed if the stenosis is greater than $50 \%$ by diameter. However, there have been no large-scale trials to determine whether correction of only 'hemodynamically' significant lesions (those associated with 'low' $\mathrm{Q}_{\mathrm{A}}$ or 'high' pressures or a change in $\mathrm{Q}_{\mathrm{A}}$ or pressure) is superior to correction of all stenoses greater than $50 \%$.

Until such studies are conducted, the value of routine use of any technique for detecting anatomic stenosis alone without concomitant measurement of $\mathrm{Q}_{\mathrm{A}}$, venous pressure, recirculation, or other physiologic parameters has not been established. Stenotic lesions should not be repaired merely because they are present. If such correction is performed, then intraprocedural studies of $\mathrm{Q}_{\mathrm{A}}$ or $\mathrm{P}_{\mathrm{IA}}$ prior to and following PTA should be conducted to demonstrate a functional improvement with a 'successful' PTA.

\section{References}

1 Huber TS, Carter JW, Carter RL, Seeger JM: Patency of autogenous and polytetrafluoroethylene upper extremity arteriovenous hemodialysis accesses: a systematic review. J Vasc Surg 2003;38:1005-1011.

-2 Perera GB, Mueller MP, Kubaska SM, Wilson SE, Lawrence PF, Fujitani RM: Superiority of autogenous arteriovenous hemodialysis access: maintenance of function with fewer secondary interventions. Ann Vasc Surg 2004;18:66-73.

3 Hakim RM, Breyer J, Ismail N, Schulman G: Effects of dose of dialysis on morbidity and mortality. Am J Kidney Dis 1994;23:661669
4 Centers for Medicare and Medicaid Services: 2003 Annual Report, End Stage Renal Disease Clinical Performance Measures Project. Baltimore, Department of Health and Human Services, Centers for Medicare and Medicaid Services, Center for Beneficiary Choices, December 2003

$\checkmark 5$ Feldman HI, Kobrin S, Wasserstein A: Hemodialysis vascular access morbidity. J Am Soc Nephrol 1996;7:523-535.

6 Rocco MV, Bleyer AJ, Burkart JM: Utilization of inpatient and outpatient resources for the management of hemodialysis access complications. Am J Kidney Dis 1996;28:250-256.

7 Schwab SJ: Assessing the adequacy of vascular access and its relationship to patient outcome. Am J Kidney Dis 1994;24:316-320.
8 McCutcheon B, Weatherford D, Maxwell G, Hamann MS, Stiles A: A preliminary investigation of balloon angioplasty versus surgical treatment of thrombosed dialysis access grafts. Am Surg 2003;69:663-667; discussion 668.

$\checkmark 9$ Sehgal AR, Snow RJ, Singer ME, et al: Barriers to adequate delivery of hemodialysis. Am J Kidney Dis 1998;31:593-601.

10 Sehgal AR, Dor A, Tsai AC: Morbidity and cost implications of inadequate hemodialysis. Am J Kidney Dis 2001;37:1223-1231.

11 http://www.kidney.org/professionals/kdoqi/ guidelines_updates/doqi_uptoc.html.

12 National Kidney Foundation: NKF-DOQI clinical practice guidelines for vascular access. Am J Kidney Dis 1997;30(suppl 2):S67. 
$\checkmark 13$ National Kidney Foundation: K/DOQI clinical practice guidelines for vascular access. Am J Kidney Dis 2001;37:S137-S181.

14 Collins AJ, Roberts TL, Peter WL, et al: United states renal data system assessment of the impact of the National Kidney Foundation Dialysis Outcomes Quality Initiative Guidelines. Am J Kidney Dis 2002;39:784-795.

15 CMS Office of Public Affairs, CMS News for Immediate Release. http://www.cms.hhs.gov/ media/press/release. asp? Counter $=1386$.

-16 Allon M, Bailey R, Ballard R, Deierhoi MH, Hamrick K, Oser R, Rhynes VK, Robbin ML, Saddekni S, Zeigler ST: A multidisciplinary approach to hemodialysis access: prospective evaluation. Kidney Int 1998;53:473-479.

17 Pflederer TA, Darras FS, Welsch K, et al: How to organize hemodialysis vascular access quality assurance efforts into a cohesive whole for better patient outcomes. Contemp Dial Nephrol 2001;1:18-21.

18 Department of Health and Human Services Centers for Medicare and Medicaid Services: Adult in-center hemodialysis patients - vascular access. 2003 Annual Report ESRD Clinical Performance Measures Project 2003, p 30.

$\checkmark 19$ Garland JS, Moist LM, Lindsay RM: Are hemodialysis access flow measurements by ultrasound dilution the standard of care for access surveillance? Adv Ren Replace Ther 2002;9: 91-98.

20 Dember LM, Holmberg EF, Kaufman JS: Randomized controlled trial of prophylactic repair of hemodialysis arteriovenous graft stenosis. Kidney Int 2004;66:390-398.

-21 Ram SJ, Work J, Caldito GC, Eason JM, Pervez A, Paulson WD: A randomized controlled trial of blood flow and stenosis surveillance of hemodialysis grafts. Kidney Int 2003;64:272280.

-22 Moist LM, Churchill DN, House AA, Millward SF, Elliott JE, Kribs SW, DeYoung WJ, Blythe L, Stitt LW, Lindsay RM: Regular monitoring of access flow compared with monitoring of venous pressure fails to improve graft survival. J Am Soc Nephrol 2003;14:2645-2653.

23 Paulson WD: Access monitoring does not really improve outcomes. Blood Purif 2005;23: $50-56$.

24 Beathard G: Physical examination: the forgotten tool; in Gray JR, Sands JJ (eds): Dialysis Access: A Multidisciplinary Approach. Philadelphia, Lippincott, Williams \& Williams, 2002, pp 111-118.

25 Schwartz C, Mitterbauer C, Boczula M, et al: Flow monitoring: performance characteristics of ultrasound dilution versus color Doppler ultrasound compared with fistulography. Am J Kidney Dis 2003;42:539-545.

-26 Tessitore N, Bedogna V, Gammaro L, et al: Diagnostic accuracy of ultrasound dilution access blood flow measurements in detecting stenosis and predicting thrombosis in native forearm arteriovenous fistulae for hemodialysis. Am J Kidney Dis 2003;42:331-341.

-27 Beathard GA, Litchfield T: Functions of a dedicated vascular access facility promoting AVF use. Nephrol News Issues 2004;11:44-48.
8 Arbab-Zadeh A, Mehta RL, Zeigler TW, et al: Hemodialysis access assessment with intravascular ultrasound. Am J Kidney Dis 2002;39: 813-823.

29 Froger CL, Duijm LE, Liem YS, Tielbeek AV, Donkers-van Rossum AB, Douwes-Draaijer P, Cuypers PW, Buth J, van den Bosch HC: Stenosis detection with MR angiography and digital subtraction angiography in dysfunctional hemodialysis access fistulas and grafts. Radiology 2005;234:284-291.

30 Smits JH, Bos C, Elgersma OE, van der Mark WA, Blankestijn PJ, Bakker CJ, Zijlstra JJ, Kalmijn S, Mali WP: Hemodialysis access imaging: comparison of flow-interrupted contrast-enhanced MR angiography and digital subtraction angiography. Radiology 2002;225: 829-834.

31 Han KM, Duijm LE, Thelissen GR, Cuypers PW, Douwes-Draaijer P, Tielbeek AV, Wondergem JH, van den Bosch HC: Failing hemodialysis access grafts: evaluation of complete vascular tree with 3D contrast-enhanced MR angiography with high spatial resolution: initial results in 10 patients. Radiology 2003;227: 601-605.

32 Bakker CJ, Bosman PJ, Boereboom FT, Blankestijn PJ, Mali WP: Measuring flow in hemodialysis grafts by non-triggered 2DPC magnetic resonance angiography. Kidney Int 1996;49: 903-905.

33 Aruny JE, Lewis CA, Cardella JF, et al: Quality improvement guidelines for percutaneous management of the thrombosed or dysfunctional dialysis access. J Vasc Interv Radiol 2003; 14:S247-S253.

34 Besarab A: Advances in end-stage renal diseases 2000. Access monitoring methods. Blood Purif 2000; 18:255-259.

-35 Paulson WD: Blood flow surveillance of hemodialysis grafts and the dysfunction hypothesis. Semin Dial 2001;14:175-180.

36 Jones SA, Jin S, Kantak A, Bell DA, Paulson WD: Mathematical model for pressure losses in the hemodialysis graft vascular circuit. J Biomech Eng 2005;127:60-66.

37 Sullivan KL, Besarab A, Bonn J, Shapiro MJ, Gardiner GA Jr, Moritz MJ: Hemodynamics of failing dialysis grafts. Radiology 1993;186: 867-872.

38 Lilly RZ, Carlton D, Barker J, Saddekni S, Hamrick K, Oser R, Westfall AO, Allon M: Predictors of arteriovenous graft patency after radiologic intervention in hemodialysis patients. Am J Kidney Dis 2001;37:945-953.

39 Spergel LM, Holland JE, Fadem SZ, McAllister CJ, Peacock EJ: Static intra-access pressure ratio does not correlate with access blood flow. Kidney Int 2004;66:1512-1516.

-40 Asif A, Gadalean FN, Merrill D, Cherla G, Cipleu CD, Epstein DL, Roth D: Inflow stenosis in arteriovenous fistulas and grafts: a multicenter, prospective study. Kidney Int 2005;67: 1986-1992.

$$
\text { (a) }
$$

41 Kanterman RY, Vesely TM, Pilgram TK, Guy BW, Windus DW, Picus D: Dialysis access grafts: anatomic location of venous stenosis and results of angioplasty. Radiology 1995; 195:135-139.

42 Besarab A, Sullivan KL, Ross RP, Moritz MJ: Utility of intra-access pressure monitoring in detecting and correcting venous outlet stenoses prior to thrombosis. Kidney Int 1995;47: 1364-1373.

-43 Schwab SJ, Oliver MJ, Suhocki P, McCann R: Hemodialysis arteriovenous access: detection of stenosis and response to treatment by vascular access blood flow. Kidney Int 2001;59: 358-362.

44 Schwab SJ, Raymond JR, Saeed M, Newman GE, Dennis PA, Bollinger RR: Prevention of hemodialysis fistula thrombosis. Early detection of venous stenoses. Kidney Int 1989;36: 707-711.

45 Lok CE, Bhola C, Croxford R, Richardson RM: Reducing vascular access morbidity: a comparative trial of two vascular access monitoring strategies. Nephrol Dial Transplant 2003; 18:1174-1180.

46 Cayco AV, Abu-Alfa AK, Mahnensmith RL, Perazella MA: Reduction in arteriovenous graft impairment: results of a vascular access surveillance protocol. Am J Kidney Dis 1998; 32:302-308.

47 Sands JJ, Miranda CL: Prolongation of hemodialysis access survival with elective revision. Clin Nephrol 1995;44:329-333.

-48 Safa AA, Valji K, Roberts AC, Ziegler TW, Hye RJ, Oglevie SB: Detection and treatment of dysfunctional hemodialysis access grafts: effects of a surveillance program on graft patency and the incidence of thrombosis. Radiology 1996;199:653-657.

49 Beathard GA: Percutaneous therapy of vascular access dysfunction: optimal management of access stenosis and thrombosis. Semin Dial 1994; 7:165-167.

50 Roca-Tey R, Samon Guasch R, Ibrik O, Garcia-Madrid C, Herranz JJ, Garcia-Gonzalez L, Viladoms Guerra J: Vascular access surveillance with blood flow monitoring: a prospective study with 65 patients. Nefrologia 2004; 24:246-252.

-51 May RE, Himmelfarb J, Yenicesu M, Knights S, Ikizler TA, Schulman G, Hernanz-Schulman M, Shyr Y, Hakim RM: Predictive measures of vascular access thrombosis: a prospective study. Kidney Int 1997;52:1656-1662.

52 Bay WH, Henry ML, Lazarus JM, Lew NL, Ling J, Lowrie EG: Predicting hemodialysis access failure with color flow Doppler ultrasound. Am J Nephrol 1998; 18:296-304

53 Wang E, Schneditz D, Nepomuceno C, Lavarias V, Martin K, Morris AT, Levin NW: Predictive value of access blood flow in detecting access thrombosis. ASAIO J 1998;44:M555M558.

54 Besarab A, Lubkowski T, Ahsan M, Lim T, Frinak S: Access flow $\left(\mathrm{Q}_{\mathrm{A}}\right)$ as a predictor of access dysfunction (abstract). J Am Soc Nephrol 1999;11:202A. 
D5 Neyra NR, Ikizler TA, May RE, Himmelfarb J, Schulman G, Shyr Y, Hakim RM: Change in access blood flow over time predicts vascular access thrombosis. Kidney Int 1998;54:17141719.

56 Wang E, Schneditz D, Levin NW: Predictive value of access blood flow and stenosis in detection of graft failure. Clin Nephrol 2000;54: 393-399.

57 Yeun JY, Depner TA: Role of access flow measurement; in Gray JR, Sands JJ (eds): Dialysis Access: A Multidisciplinary Approach. Philadelphia, Lippincott, Williams \& Williams, 2002, pp 119-132, table 19.3.

$\checkmark 58$ Chang CJ, Ko YS, Ko PJ, Hsu LA, Chen CF, Yang CW, Hsu TS, Pang JH: Thrombosed arteriovenous fistula for hemodialysis access is characterized by a marked inflammatory activity. Kidney Int 2005;68:1312-1319.

-59 Molino D, De Lucia D, Marotta R, Perna A, Lombardi C, Cirillo M, De Santo NG: In uremia, plasma levels of anti-protein $\mathrm{C}$ and antiprotein $\mathrm{S}$ antibodies are associated with thrombosis. Kidney Int 2005;68:1223-1229.

60 Garrancho JM, Kirchgessner J, Arranz M, Klinkner G, Rentero R, Ayala JA, Marcelli D: Haemoglobin level and vascular access survival in haemodialysis patients. Nephrol Dial Transplant, in press.

-61 Lumsden AB, MacDonald MJ, Kikeri D, Cotsonis GA, Harker LA, Martin LG: Prophylactic balloon angioplasty fails to prolong the patency of expanded polytetrafluoroethylene arteriovenous grafts: results of a prospective randomized study. J Vasc Surg 1997;26:382 390; discussion 390-392.

62 Martin LG, MacDonald MJ, Kikeri D, Cotsonis GA, Harker LA, Lumsden AB: Prophylactic angioplasty reduces thrombosis in virgin ePTFE arteriovenous dialysis grafts with greater than $50 \%$ stenosis: subset analysis of a prospectively randomized study. J Vasc Interv Radiol 1999; 10:389-396.
63 Bay WH, Van Cleef S, Owens M: The hemodialysis access: preferences and concerns of patients, dialysis nurses and technicians, and physicians. Am J Nephrol 1998;18:379-383.

64 Rocco MV, Bleyer AJ, Burkart JM: Utilization of inpatient and outpatient resources for the management of hemodialysis access complications. Am J Kidney Dis 1996;28:250-256.

65 Tessitore N, Lipari G, Poli A, Bedogna V, Baggio E, Loschiavo C, Mansueto G, Lupo A: Can blood flow surveillance and pre-emptive repair of subclinical stenosis prolong the useful life of arteriovenous fistulae? A randomized controlled study. Nephrol Dial Transplant 2004 19:2325-2333.

66 Tessitore N, Mansueto G, Bedogna V, Lipari G, Poli A, Gammaro L, Baggio E, Morana G, Loschiavo C, Laudon A, Oldrizzi L, Maschio G: A prospective controlled trial on effect of percutaneous transluminal angioplasty on functioning arteriovenous fistulae survival. J Am Soc Nephrol 2003;14:1623-1627.

67 Schwarz C, Mitterbauer C, Boczula M, Maca T, Funovics M, Heinze G, Lorenz M, Kovarik J, Oberbauer R: Flow monitoring: performance characteristics of ultrasound dilution versus color Doppler ultrasound compared with fistulography. Am J Kidney Dis 2003;42: 539-545.

68 Besarab A, Dorrell S, Moritz M, Michael H, Sullivan K: Determinants of measured dialysis venous pressure and its relationship to true intra-access venous pressure. ASAIO Trans 1991;37:M270-M271.

69 Smits JH, van der Linden J, Hagen EC, Modderkolk-Cammeraat EC, Feith GW, Koomans HA, van den Dorpel MA, Blankestijn PJ: Graft surveillance: venous pressure, access flow, or the combination? Kidney Int 2001;59:15511558.

70 NKF guidelines for vascular access, 2006, in preparation.
Finlay DE, Longley DG, Foshager MC, Letourneau JG: Duplex and color Doppler sonography of hemodialysis arteriovenous fistulas and grafts. Radiographics 1993;13:983-989.

72 Kirschbaum B, Compton A: Study of vascular access blood flow by angiodynography. Am J Kidney Dis 1995;25:22-25.

73 Hoeben H, Abu-Alfa AK, Reilly RF, Aruny JE, Bouman K, Perazella MA: Vascular access surveillance: evaluation of combining dynamic venous pressure and vascular access blood flow measurements. Am J Nephrol 2003;23:403408.

74 Beathard GA: The treatment of vascular access graft dysfunction: a nephrologist's view and experience. Adv Ren Replace Ther 1994;1:131147.

75 Windus DW, Audrain J, Vanderson R, Jendrisak M, Picus D, Delmez JA: Optimization of high-efficiency dialysis by detection and correction of vascular access dysfunction. Kidney Int 1990;38:337-341.

76 Besarab A, Ross R, Al-Aljel F, Deane C, Frinak $\mathrm{S}$, Zasuwa G: The relation of brachial artery flow to access flow (abstract). J Am Soc Nephrol 1995; 7:483A.

77 Besarab A, Sherman RA: The relationship of recirculation to access blood type. Am J Kidney Dis 1997;29:223-229.

78 Grogan J, Castilla M, Lozanski L, Griffin A, Loth F, Bassiouny H: Frequency of critical stenosis in primary arteriovenous fistulae before hemodialysis access: should duplex ultrasound surveillance be the standard of care? J Vasc Surg 2005;41:1000-1006.

79 Trerotola SO, Scheel PJ Jr, Powe NR, Prescott C, Feeley N, He J, Watson A: Screening for dialysis access graft malfunction: comparison of physical examination with US. J Vasc Intery Radiol 1996; 7:15-20.

80 Beathard GA: Physical examination of AV grafts. Semin Dial 1996;5:74. 